\title{
$\begin{array}{r}\text { WAGENINGEN } \\ \hline\end{array}$
}

\section{Precaution Needs to Abound, Not Wither}

\author{
Lahsen, M.
}

This is a "Post-Print" accepted manuscript, which has been Published in

"Environment: Science and Policy for Sustainable Development"

This version is distributed under a non-commercial no derivatives Creative Commons (c) (1) () $\odot$

(CC-BY-NC-ND) user license, which permits use, distribution, and reproduction in any medium, provided the original work is properly cited and not used for commercial purposes. Further, the restriction applies that if you remix, transform, or build upon the material, you may not distribute the modified material.

Please cite this publication as follows:

Lahsen, M. (2017). Precaution Needs to Abound, Not Wither. Environment: Science and Policy for Sustainable Development, 59(5), 2-3.

https://doi.org/10.1080/00139157.2017.1354635

You can download the published version at:

https://doi.org/10.1080/00139157.2017.1354635 
Lahsen, M. 2017. "Precaution Needs to Abound, Not Wither." Environment: Science and Policy for Sustainable Development, September-October.

\section{Precaution Needs to Abound Not Wither}

The Trump administration has decided to withdraw from the Paris Agreement and to weaken regulatory safeguards and scientific input by subordinating both to control by representatives of the very industries from which societies need greater protection. Its decisions are particularly monumental and strident instances of today's global and systemic environmental and social destruction. Currently, humanity uses up the annual planetary "budget" to pollute and produce goods within an ever shrinking period - or "sustaining year" - which now ends in early August. Pesticides used in Latin America are generating unprecedented rates of cancer and birth defects. Degrading ecosystems and the resources the latter sustain, they also threaten food, water and energy security. The cancerous rationality of deeply corrupt political leaders in important parts of this region lead them to ignore or reconstruct scientifically well-grounded evidence. As they and Trump make painfully obvious, many decision makers are disinclined to be persuaded. Not all scientists are as aware of that as they should, preventing sufficiently hard thinking about what to do to improve decision making in such "post-truth" contexts of willful ignorance.

The need for precaution and trend reversal has never been greater. The precautionary principle offers a framework for organized skepticism with regard to innovations, a framework that privileges the goals of healthy ecosystems and humans, including the rights and welfare of future generations. The adoption of the precautionary principle in law and regulations - or the lack thereof - is hugely consequential. The precautionary principle is not explicitly mentioned in U.S. federal legislation and policies (Gonçalves, 2013). Even where it has been adopted, such as in declarations under the United Nations and in European Union legal frameworks, its formulation needs to be strengthened.

The contributors note the irony and potential tragedy in the fact that the precautionary principle is being profoundly and progressively weakened at a time when it sorely needs strengthening. With reference to a range of cases - synthetic chemicals, genetic engineering and climate change - they discuss pathways and leverage points for achieving that. A key message is that the precautionary principle needs to become a formal, legal requirement in national and international laws and regulations, not merely a legally supported option. Boswell analyzes how the precautionary principle has been invoked in legal affairs, as society grapples with financial liabilities caused by corporate decision making that is, or ought to be, inflected by the emerging realities of climate change. Daramus points out that economic actors who embrace the low-carbon shift also tend to reduce their vulnerability to subsequent lawsuits. Both contributors see litigation is a key force in favor of more precautionary environmental decision making. 
Examining the case of new genetic engineering techniques, Steinbrecher and Paul stress the need to counter current business pressures on governments to override the precautionary principle in favor of the 'innovation principle.' Touching on a recurrent theme in this issue's contributions, they urge installment of new processes allowing deep, critical examination of the implications of technologies, and the possibility of deciding against their deployment in some cases. The same argument is often heard with regards to Solar Radiation Management technologies. The Trump administration's current interest in the latter - despite the huge geophysical (Irvine et al., 2010) and ethical (Corner and Pidgeon, 2010) implications of their wholesale application - underscores the importance of implementing such precautionary processes across the board. Chapman points out that there are ethical dimensions and lessons learned from EU governance of synthetic chemicals that can be brought to bear on the design of such processes. Higher standards of risk assessment should apply where the health of humans and ecosystems are endangered, she argues, and there should be greater liability on the part of those generating novel products.

Realizing such changes will likely depend on policies to ensure higher levels of public participation. New actors are needed to push decision makers and, even, scientists, out of their current dependencies and comfort zones, which too often favor status quo rather than precaution. Read and O'Riordan - leading, seasoned analysts of the precautionary principle remind us that it came into being precisely to fill a dangerous gap in policy processes at all scales provoked by an absence of appropriate methodologies for scientific assessment and political inattention to the 'distributional aspects' and dangers of techno-scientific developments. There is no other legal or regulatory framework for ensuring human empathy and "deep future-care" of the sort so urgently needed and widely called for. The precautionary principle imposes an ethic of planetary care, rigorous impact assessments and public discussion and deliberation over deeper stakes - including what kind of society and moral accountability we collectively should choose to adopt. Now is the time to act on it.

\section{Myanna Lahsen}

\section{REFERENCES}

CORNER, A. \& PIDGEON, N. 2010. Geoengineering the climate: the social and ethical implications. Environment: Science and Policy for Sustainable Development, 52, 24-37.

GONÇALVES, V. B. 2013. The precautionary principle and environmental risk management: contributions and limitations of economic models. Ambiente \& sociedade, 16, 121-138.

IRVINE, P. J., RIDGWELL, A. \& LUNT, D. J. 2010. Assessing the regional disparities in geoengineering impacts. Geophysical Research Letters, 37. 